\title{
Measuring the Effect of Direct and Indirect Costs on the Revenues of Kofa Cement Factory using the Multi Linear Regression Technique
}

\author{
${ }^{1}$ Hameed Ali Saleh, ${ }^{1}$ Abdul Qader Nayef Taayyh and ${ }^{2}$ Ali Nasser Alwan \\ ${ }^{1}$ Department of Accounting, Al-Isra'a University, Baghdad, Iraq \\ ${ }^{2}$ Business Administration, Al-Isra'a University, Baghdad, Iraq
}

\begin{abstract}
The research aims to measure the effect of changes in direct and indirect costs on revenues of production. The descriptive approach and the standard economic measurement approach were used in the formation of the model based on the multiple regression method in the analysis of Kofa Cement Factory data for the year 2016. The regression equation was estimated by using the least squares method. The results showed that the direct and indirect costs affected the revenues of production. This indicates that the independent variables direct and indirect costs explain the changes occurred in the revenues. The study recommended the necessity of adopting the variable (direct) cost method to determine the costs that vary with the volume of activity and those being charged on the revenues because fixed costs are period costs as well as the adoption of the variable cost in pricing the product after taking into consideration the wishes of customers and the behavior of competitors.
\end{abstract}

$\underline{\text { Key words: } \text { Cost accounting, cost management, management accounting, cost classification, variable, necessity }}$

\section{INTRODUCTION}

The development of the managerial techniques in business companies used in the accounting and financial measurement, especially, after the industrial revolution and the consequent, large-scale projects, technological progress, diversity of production, global competition. It is imperative for these companies to identify and classify the costs of production accurately for providing detailed cost information which reflects accuracy the consumption of available resources. These detailed costs reflect the costs of producing products and provide good information for decision making purposes.

Accordingly, this part describes problem, objective, importance and hypothesis of the research within the scope of measuring the effect of direct and indirect costs on the revenues of production in Kofa Cement Factory.

Problem of research: A contemporary company faces a strong competition from local and foreign companies. In order to maintain its market share and enhance its competitive position, it is important to understand the need and importance of costs. Hence, the research problem arises in determining the extent of effect of direct and indirect costs on sales revenue. In fact, costs play a significant role in identifying the opportunities needed to be reduced and establish the most competitive selling prices.

Objective of research: The objective of the research is to use the linear regression method to determine which of the direct and indirect costs that have a significant effect on sales revenue.
Importance of research: This research is considered important because it deals with the costs related to one of the important sectors on which most of the countries depend in achieving economic development that is the industrial sector. Thus, this research is an attempt to draw the attention of management of companies to the extent of the relationship between the costs of the consumed resources and the revenues and explain the behavior of costs to make sound economic decisions.

Hypothesis of research: The research assumes that there is a statistically significant relationship between the direct and indirect costs with revenues and that there is a positive effect for both direct costs and indirect costs on sales revenue.

The following part of the research discusses the theoretical aspect to explain the concept, elements and flow of costs within the production process as well as definition of factors affecting the sales revenue (price). Next, the research methodology is described. Then, the practical aspect is examined to show the results related to the effect of both direct and indirect costs on the revenues of production using the multiple regression technique. Finally, the most important conclusions and recommendations is explained.

Production costs within the manufacturing process: This study discusses in the following subsections the theoretical aspect of the research to explain the concept, elements and flow of costs within the production process as well as the definition of factors affecting the sales revenue. 
Cost concept in the accounting and economic perspective: The concept of cost varies according to the objective that the costs will be used for thus, there is no specific meaning of cost. But the most common definition of cost in the literature of cost and management accounting is the monetary value provided for obtaining a current commodity or service or future benefits. It appears that cost represents flows of resources such as cash or future financial obligation, to pay, for example, salaries. Such flows lead to benefits, for example, raw materials or machinery used in manufacturing products which are sold to generate cash benefits (Atkinson et al., 2007) The definition of cost in economic terms is defined as the expected value of alternatives that were abandoned as a result of choosing certain alternative. It is used in evaluating alternatives and decision making (Zayer, 2017). It can be said that it is a benefit related to the future obtained from an alternative that has been abandoned. Thus, it is perceived as the cost of the lost opportunity. Therefore, the cost in the economic perspective is broader and more comprehensive than the meaning in the accounting perspective.

Elements of manufacturing cost: Regardless of size of the company, diversification of products and type of the production system, the costs of production process consist of three basic elements. These elements are as follows:

Direct materials: These are all materials that can be traced in the production of goods or delivery of service. The costs of these materials can be directly charged on products or services because the physical control can be used to measure the quantity consumed for each product. Materials that become part of a tangible product or materials consumed in providing the service are usually classified as direct materials, for example, steel in the automotive industry, wood in furniture, cloth in the clothes industry (Shukla et al., 2008).

Direct labor: These are all wages that can be traced to the production of goods or delivery of services that are directly charged to the products or services because of a material correlation that can be used to measure the amount of work (hours worked) consumed to make a product or service. These represent the amounts paid to workers who convert the raw materials to a final product or service rendered to customers, for example, wages of a chief chef in a restaurant or wages of the nurse for a surgery operation.

Indirect costs: These costs can not be directly traced and linked to a cost object or cost unit. That is costs that can not be directly charged to a production order, process, service or center because they are general expenses called indirect manufacturing expenses as defined by the Chartered Institute of Management Accountants, CIMA such as all manufacturing costs except direct materials and direct labor. Example of indirect manufacturing costs include indirect materials, indirect wages, rent, taxes, depreciation, maintenance, repair, supervision as well as selling, distribution and marketing expenses (Walther and Skousen, 2009.

Costs not associated with operating processes: Non-manufacturing costs are usually categorized into administrative and marketing costs. The administrative costs include all costs not directly incurred in production or sale. Examples of these costs include salaries paid to employees at management, stationery, publications, communications, rent, repair and depreciation of general buildings, etc. The marketing costs include selling and distribution costs. The selling costs comprise all the expenditures incurred in order to create, motivate and guarantee orders. Examples of marketing costs are: sales employee's salaries, advertising, packaging, promotion, commission of sales agents, showroom expenses and others. The distribution costs include all the expenditures incurred by the company from the moment the product flowed from the factory to reach the customer. The marketing costs are called "period costs" (Shukla et al., 2008).

The importance of cost classification: Cost items are classified and arranged in logical groups on the basis of similarities in nature or characteristics. Costs are always used for different purposes or objectives. The classification of costs helps to achieve certain purpose that may not be suitable for another purpose.

Cost flow in manufacturing companies: When costs are classified on the basis of a direct and indirect relationship with an object, they are treated as product costs irrespective of the related cost behavior. So, the performance results presented through the income statement do not distinguish between variable and fixed costs but are presented as production costs (Al-Fadagh, 2013).

The cost of production should clearly reflect the resources consumed in the manufacturing process. It is simple, if a company uses all the materials purchased to produce a single product and sales all the units that have been manufactured, then income will be relatively easy to calculate. However, when a company produces multiple products and does not sale all of the products manufactured as well as the existence of work-in-process the matter becomes more complicated. When a company evaluates the profitability of products and looks for opportunities to reduce cost and determine the mix of sales and assesses special orders and pricing, the costs of these decisions will require a high degree of accuracy at the level of each product separately. 
To determine the cost of products accurately, the manufacturing costs of each product must be individually traced and allocated. Then, the cost of the product is to be traced and controlled by the inventory accounts until it reaches the completion in order to be sold. When the product manufactured reaches the sales point its costs of production (cost of goods sold) should be matched with its sales revenue to calculate the income account (profit/loss). However, when all of the finished goods are not sold or the work-in-process is not fully manufactured, the costs must be calculated through raw materials or work-in-process inventory or finished goods inventory.

The product cost refers to all the costs that can be assigned to the product for a particular purpose and includes (direct materials, direct labor and indirect manufacturing expenses). A company wishes to precisely determine costs for cost purposes because the inaccurate product costs mislead management in different purposes. So, different purposes of product costs can produce different measures (Charles et al., 2015).

Costs are the basis of pricing decisions: The product cost represents the minimum sale price of the product. Therefore, the determination of revenues of products has a relevant relationship with costs through sale prices. There are two approaches for companies to determine the prices of selling their products in a manner that covers their costs and achieves an economic surplus.

First, the target cost approach: This approach starts with the total costs targeted at the market price "that the customer is willing to pay" minus the profit required to determine the total target costs. That is to say all the costs incurred by the products through the value chain. These represent the total costs of developing, designing, producing, marketing and rendering service:

$$
\begin{aligned}
& \text { Market sale price }=\text { total target } \\
& \text { costs-required profit or }
\end{aligned}
$$

$$
\begin{aligned}
& \text { Total target costs }=\text { revenue at market } \\
& \text { price-required profit }
\end{aligned}
$$

If costs of the product exceed the target cost, the management has to find ways to reduce costs by reference to the value chain in addition to Activity Based Costs, $\mathrm{ABC}$, otherwise it does not make a profit.

Second, total costs and profit approach: Unlike the target price approach adopted by leading companies, this approach starts with the total costs and profit. In order to determine the price, companies that establish prices may take one of the two techniques:
The pricing technique under the total costs method determines the price according to the following equation:

$$
\begin{aligned}
& \text { Pricing by total costs: total costs }+ \\
& \text { required profit }=\text { sales revenues }
\end{aligned}
$$

The pricing technique under the variable cost method determines price according to the following equation: Pricing by costs and profit: total variable costs+required profit $=$ sales revenues $($ Jawahar Lal, 2008).

Factors affecting revenues of production: Revenue is the value of what the company gets as a result of the sale of its products that is it represents the value of sales. The price demanded by the company depends on the value that equals the product for the customer. There are three factors controlling the value (price) of a produc.

First, customer's request: The company's action is to understand the customer's requests as a continuous and very important processes. For the purpose of understanding the requests of customers management obtains information from market research such as customer's surveys and marketing campaigns as well as information collected from the sales staff.

Second, competitor's actions: Forecasting competitor's reactions towards product design and pricing strategy is difficult but it is an important action to manage the company when setting competitive prices because alternative products can affect demand and force others to lower their product prices (Hilton, 2008).

When studying the reactions of customers and competitors the company's management should appropriately set the prices of its products and determine the pricing demand elasticity.

If the company wants to raise the price of a particular product will this action encourage potential customers to switch to another product? Or will most customers react to price increases and shift to competing producers?

Third, costs: Costs affect the determination of prices because they affect the quantity of supply. The low cost of producing a product is related to the price and the quantity of units that the company wishes to offer. The management that is able to understand the cost structure of its products, it can determine prices that attract customers and thus maximize revenues (Charles et al., 2015). Charles et al. (2015) and Jawahar (2008) pointed out that the most influential factor in a pricing decision is the value the customer will derive from the consumption of the product that reflects the customer's willingness to pay. While, Hilton (2008) emphasizes the balance between the forces of the market and costs as both market forces and costs have significant effect on prices. 
Management cannot set the prices of products without determining the costs of production. Also, it does not set the prices of products blindly on the basis of cost plus without consideration of the market. Pricing is determined using one of two methods: setting prices through the market should cover the costs in the long-term that is when the company takes the price and setting prices through costs should take into account reactions of customers and competitors.

Accordingly, it can be said that there are several factors affecting pricing, the most important of which is the costs that are a decisive factor in the decision making of pricing. Further, the nature of industry cannot be excluded whether it is in a fully competitive market or monopoly market competition where the latter has a clear effect on the possibility of setting prices.

\section{MATERIALS AND METHODS}

This study describes the case study data collection and the way of building the statistical model.

Research case: Kofa Cement Factory is selected for the case study. It is one of the factories of the general company for Iraqi cement which is one of the formations of the Ministry of Industry and Minerals in Iraq. This company was selected for this research for a number of justifications: the role of the company and its factories in supporting the Iraqi national economy by providing a product related to the life of the consumers the cement industry is one of the most competitive industries in the local markets: the company possesses accumulated experience in the field of cement industry which requires the provision of a product to the consumers at high quality and at a competitive price.

Moreover, in terms of accounting aspect, the company was chosen as having a cost accounting system that works according to the Iraqi unified accounting system.

Data collection and analysis methods: In order to achieve the research objective, the practical aspect of the research was based on the costs and revenues data collected from the records of the general company for Iraqi cement. The simple regression technique was applied on the collected data to test its hypothesis. The regression equation was estimated by using the Least Squares Method (LSM). In addition, a number of personal interviews with the production manager, chief accountant were conducted.

Building the standard model: The formulation of the standard model is considered one of the most important stages of building the model due to the determination of the variables that it includes. At this stage, the relationship is estimated and analyzed by means of the multiple regression equation using eViews program whose importance stems from the economic life reality, indicating that the phenomenon is not affected by one variable but rather there is a set of independent variables that affect the phenomenon. Hence, the multiple regression technique reflects the real reality with which the phoneme under consideration deals with and its response to a range of affecting factors. With regard to the standard model of the phenomenon under study, it is limited by the following variables:

$$
\mathrm{TR}=\mathrm{f}(\mathrm{DC}, \mathrm{IC})
$$

This equation implies that the variables can be determined by the dependent variable "Total Revenues" (TR) and the independent variables.

"Direct Costs" (DC) and "Indirect Costs" (IC). In light of these variables, the multiple regression technique will be used to estimate the standard model, according to the linear formula and its form is as follows:

$$
\mathrm{TR}=\mathrm{b} 0+\mathrm{b} 1+\mathrm{b} 2+\mathrm{Ui}
$$

where $b 0, b 1$ and $b 2$ are parameters of the model

As the model is probabilistic in nature, the error limit (ui) was included to represent the variables that are difficult to quantify the estimation results of the model. Accordingly, accuracy of the parameters is examined and the following hypothesis is tested:

$$
\mathrm{H}_{0}: \mathrm{B}_{\mathrm{i}}=0, \mathrm{H}_{1}: \mathrm{B}_{\mathrm{i}} \neq 0 \text { and } \mathrm{I}=0,1,2
$$

\section{RESULTS AND DISCUSSION}

This study first describes the stages of manufacturing cement in Kofa Cement Factory and then discusses results of the research.

Description of the stages of manufacturing cement in Kofa Cement Factory: The process of manufacturing cement consists of the following stages. First, quarry the process includes two types:

Ordinary soil quarry: The process involves investigating the locations of silica quality $\mathrm{SiO}_{2}$ which is suitable for the production of cement and then the soil is removed and transported to the main stores material (mills stores).

Limestone quarries: The process involves investigating the locations of calcium carbonate $\mathrm{CaCo}_{3}$ quality with a percentage not $<97 \%$, then it is taken off, broken and transferred to the main quarry crusher. 


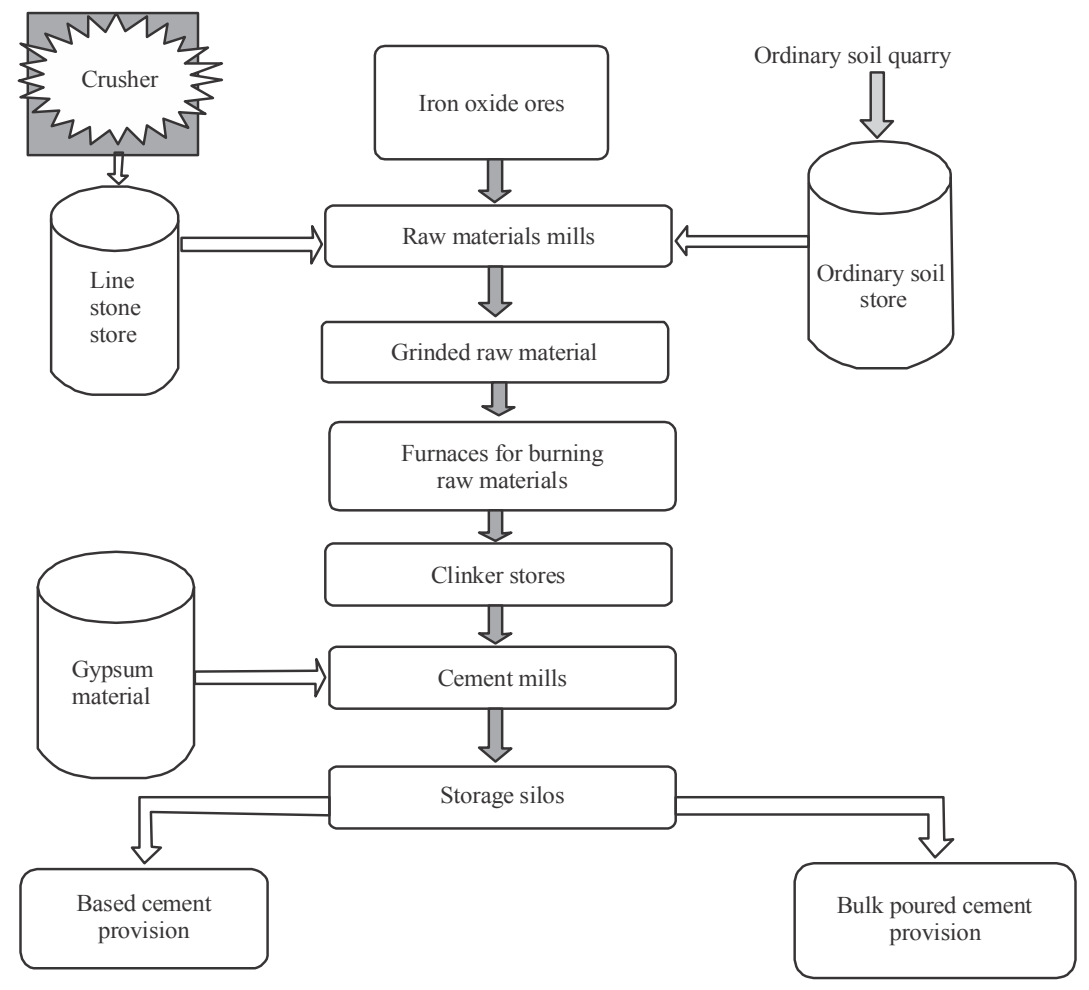

Fig. 1: Production process chart

Second, the main quarry crusher (raw materials): The large pieces of limestone are broken in this main quarry crusher to be suitable for feeding raw materials mills.

Third, mills of raw materials: The raw materials are grinded and crushed in these mills to reach the state of softness required for the purpose of burning them in furnaces.

Fourth, grinded raw materials stores: In these stores the raw materials are mixed to achieve the state of homogeneity and smoothness of the quality required for the purpose of burning them in the furnaces.

Fifth, furnaces of incineration of raw materials: In these furnaces the mixture of raw materials are burnt and roasted to reach the degree of saturation coefficient of calcinations with an acceptable coefficient of combustion and gives good qualitative specifications when grinding clinker in cement mills.

Sixth, clinker stores: The clinker material is stored for the purpose of homogenizing the quality and obtaining suitable mixtures for the production of cement conforming to the standard quality specifications.

Seventh, adding gypsum: In this stage the tripartite calcium sulfate is added to delay the hardening time of cement resulting from mixing with clinker to obtain a specific hardening time after the mixing of cement with water.

Eighth, cement mill: In this stage, the clinker granules are crushed and softened with calcium sulphate (gypsum) to the limits of the standard cement specification.

Ninth, reservoirs (silos) of cement: The grinded cement, available for marketing and meeting the specifications is stored in the vertical isolated silos to be protected from the factors of humidity and external conditions.

Tenth, provision of cement: The process involves two methods:

Provision of cement by way of bulk pouring: The cement is provided from the main silos by way of bulk pouring a truck specified for transporting cement without packaging and delivering it to the customer for constructional use.

Provision of cement by the method of casing: The cement is provided from the main silos in a manner of bagging in bags of $50 \mathrm{~kg}$ per bag and are loaded on the back of specialized trucks and delivered to the customer for public consumption (Fig. 1). 
Int. Business Manage., 13 (7): 300-306, 2019

Table 1: Direct and indirect costs for the fiscal year 2017

\begin{tabular}{lccccccr}
\hline Months & Direct cost/ton & Total direct cost & Materiality & Indirect costs & Total indirect cost & Materiality & Total monthly revenue \\
\hline January & 35000 & 1538953500 & 46 & 41300 & 1815965130 & 54 & 3693487210 \\
February & 35000 & 1944474777 & 46 & 41387 & 2299970780 & 54 & 4668072148 \\
March & 35343 & 4448927360 & 46 & 41257 & 5193373400 & 54 & 10573805036 \\
April & 37667 & 4088368647 & 47 & 42055 & 9117349043 & 53 & 4564641289 \\
May & 38200 & 4160472780 & 48 & 41791 & 9148687704 & 52 & 4551579004 \\
June & 38220 & 3812234504 & 48 & 41122 & 7782716180 & 52 & 3812234504 \\
July & 39103 & 3174999367 & 50 & 39150 & 6820448896 & 50 & 3178815570 \\
August & 39300 & 3310309740 & 50 & 39140 & 7075470758 & 50 & 3296832652 \\
September & 39689 & 2438007954 & 48 & 42099 & 2586048952 & 52 & 5159937316 \\
October & 37338 & 2918636784 & 46 & 43260 & 3381547680 & 54 & 6566114868 \\
November & 35050 & 2150629445 & 41 & 50600 & 3104760340 & 59 & 5154155790 \\
December & 35930 & 2305351439 & 45 & 43594 & 2797091306 & 55 & 5389636198 \\
\hline
\end{tabular}

Estimation and analysis of the relationship between revenues and direct and indirect costs: Management of the factory always wants to estimate the production costs before the occurrence of actual production, i.e., before knowing the actual costs in disputable manner. Obtaining data related to costs is considered very important for determining prices (Revenues). The general cement company as a parent company, classifies its costs as direct and indirect and uses cost-plus method because it centrally applies the total cost approach in setting prices. The costs of production (cost components) are divided into three main components: raw material costs, labor costs and indirect costs. These components exist in any industry but the relative importance of these components varies from industry to industry according to the nature of the industry and the product. Table 1 shows the cost structure of raw materials as follows.

The direct costs (direct materials and direct labor) per ton were unstable. This was due to instability of the prices of raw materials and changes in salaries of employees as a result of bonuses and promotions.

The relative importance of indirect manufacturing costs in terms of the largest contribution in the total manufacturing costs throughout the year except July and August. In these 2 months the relative importance of the cost components was equal due to the low share of ton of non-fixed manufacturing costs as a result of the increase in the quantities produced.

The average relative importance of the direct costs component amounted to $48 \%$ while the relative importance of the component of indirect costs amounted to $52 \%$ in reference to the large contribution of indirect costs in raising the total manufacturing costs of the product in question.

In order to measure and analyze the effect of direct and indirect costs on total production revenues, the multiple linear regression technique and the least squares method were used to determine which costs have a greater effect on revenues, discover the available opportunities to reduce the costs of production, determine the larger part of these costs (cost components materiality), provide the best results in minimizing error variance, estimate and analyze the relationship between the variables of the statistical model.
The tbi calculated value of 1.812 related to estimated parameter was compared with its tabulated one, at a significant level of $5 \%$ and a degree of freedom 10 . It was clear that the null hypothesis was accepted and the alternative hypothesis of parameter b1 was rejected. Where the calculated $t$ was $<0.91$ which was less than its tabulated one. However, this result was not statistically significance. While, the calculated value of parameter b2 amounted to 2.137 which is larger than its tabulated value at a significant level of $5 \%$, indicating its statistical significance.

As for $\mathrm{R}^{2}$ parameter of 0.96 that indicated $96 \%$ of the dependent variable was explained by the independent variables. In other words, $96 \%$ of the changes occurring in total revenues were due to changes in both direct and indirect costs and the remaining $4 \%$ was due to other variables not included in the model.

The calculated $\mathrm{F}$ value of 111.9 was compared with its tabulated value of 4.10 at a significance level $5 \%$ and a degree of freedom 11 . The alternative hypothesis was accepted and the null hypothesis was rejected. This indicated that an existence of an effect relationship between the independent variables on the dependent variable and therefore the linear relationship is significant. The Durban-Watson (DW) test's calculated value of 1.18 was compared with its tabulated value at 5\% significance level and a degree of freedom 11. It was shown that it fell within the limits of du<DW $<4$-du. Therefore, the alternative hypothesis was rejected and the null hypothesis was accepted. This result indicated that there was no self-correlation between the successive values of the random variable.

To determine the effect of each of the independent variables on the dependent variable "total revenue", the estimated parameters of the model showed that the constant b0 of 0.99 , indicated that other factors which affect the dependent variable are not included in the model. The direct cost factor b1 was noted that its sign was positive which was appropriate to the nature of the research sample product. This indicated that any increase in the direct costs by one unit resulted in an increase in revenue by 0.68 , namely that the increase in revenue was less than the increase in the direct costs. This drives the factory to work on reducing the direct costs through, for 
example, restoring the technical composition of the product, searching for new sources for supplying raw materials with high quality and low cost and work on the optimal exploitation of the direct labor element.

The indirect cost parameter $\mathrm{b} 2$ indicated that its sign was positive. This indicated that any increase in indirect costs by one unit resulted in an increase in revenues by the amount of the slope coefficient of 1.28 indicating that there was an increase in revenues due to the increase in indirect cost that was beneficial. Thus, it is suggested that the company has to work to increase the efficiency of the operating activities, resulting in increased costs which is directly reflected in revenues.

Conclusion and recommendations: The research reached a number of conclusions and recommendations. These were as follows.

\section{CONCLUSION}

The research concluded that the linear regression technique showed that a relationship existed between both types of costs and revenues. This is consistent with the logic of economic theory on the basis that the data that were adopted represented the production function in the short term. From the accounting aspect, the results were consistent with the accounting logic where the research sample company classified costs according to their relationship to the product unit to direct and indirect and were collected during the period of occurrence and matched with the revenues of that period in accordance with the matching principle.

It was clear from the application of linear regression equation and the adoption of the company data that the factory in question did not distinguish between the costs in the short or long term because it used the full cost method of determining the cost of the product.

The adopted data of the company which included fixed and variable production elements represented a short-term production function. Therefore, any increase in variable costs leaded to an increase in production and revenue on the basis that the capacity of the factory still absorbed any increase in costs.

The sample company depends on costs as a major factor in the composition of revenues without considering other factors that affected revenues such as the wishes of customers and the behavior of competitors because of their impact on the sale price and the number of units sold.

\section{RECOMMENDATIONS}

The research recommended that the linear regression technique was applied because of its role in determining which costs have the greatest effect on revenues in order to ensure that revenues remain at the same value with the cost reduction of some activities. Further, there is a need to distinguish between variable and fixed costs and the adoption of the variable cost method to determine the costs that vary with the volume of activity and those charged on revenues on the basis that the fixed costs are cost period. In addition, the variable cost method adopting should be adopted in pricing the product taking into consideration the wishes of customers and the behavior of competitors. Moreover, the company should carry out advertising campaigns to promote the product and attract customers to increase the company's revenues through the increase of its sales.

\section{REFERENCES}

Al-Fadagh, F., 2013. Management Accounting, Basic Concepts. Al Rowad For Publishing \& Distribution, Aman, Jordan,.

Atkinson, A.A., R.S Kaplan, E.M. Matsumura, S.M. Young and G.A. Kumar, 2007. Management Accounting. 5th Edn., Pearson Education, Chennai, Delhi, India, ISBN:978-81-317-1656-4, Pages: 677.

Charles, T.H., S.M. Datar and M.V. Rajan, 2015. Cost Accounting: A Managerial Emphasis. 15th Edn., Pearson Education Inc., Fort Worth, Texas, USA., ISBN:9780133428704, Pages: 938.

Hilton, R., 2008. Managerial Accounting: Creating Value in a Dynamic Business Environment. 7th Edn., McGraw-Hill, New York, USA.,.

Jawahar, L., 2008. Advanced Management Accounting: Text Problems and Cases. S. Chand and Company Limited, Ram Nagar, New Delhi, India, ISBN:978-93-525-3308-4,.

Shukla, M.C., T.S. Grewal and M.P. Gupta, 2008. Cost Accounting: Text and Problems. 10th Edn., S. Chand \& Company Pvt. Ltd., Ram Nagar, New Delhi, India, ISBN:9788121919630, Pages: 963.

Walther, L.M. and C.J. Skousen, 2009. Managerial and Cost Accounting. Bookboon Company, London, UK., ISBN:978-87-7681-491-5, Pages: 130.

Zayer, A., 2017. Economics of Business, Foundations and Applications. 2nd Edn., Dar Al Kotob Al Ilmiyah Publishing, Bagdad, Iraq,. 